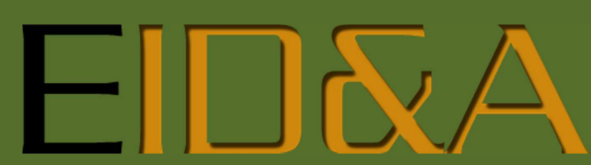

Revista Eletrônica de Estudos Integrados em Discurso e Argumentação

dx.doi.org/10.17648/eidea-16-2216

\title{
DITADURA NO BRASIL E PRODUÇÃO DE MEMÓRIAS: O PAPEL DA GRANDE MÍDIA NA CONSTRUÇÃO DE SENTIDOS HISTÓRICOS
}

Israel de Sái

Resumo: A mídia jornalística, em nossa sociedade, tem um papel fundamental: além da produção e circulação de informações, da reprodução de acontecimentos contemporâneos, inscreve-se como sujeito na construção da história do presente e na produção e reconfiguração de memórias. Neste trabalho, analisamos a produção de memórias, pela chamada grande mídia, da ditadura-civil militar brasileira. Por meio do arcabouço teórico da Análise do Discurso de linha francesa, sustentada nos trabalhos de Michel Pêcheux e seu grupo, em diálogo com Michel Foucault e a Nova História, analisamos textos produzidos pelos jornais Estado de São Paulo e Folha de São Paulo e pela revista Veja nos momentos de debates sobre a possível revisão da Lei de Anistia, em 2010, e a criação da Comissão Nacional da Verdade, em 2012. Verificamos, com isso, uma reconfiguração nessa produção, deslocando-se do discurso oficial e abrindo possibilidades para a emergência de memórias da resistência.

Palavras-chave: Memórias. Mídia. Ditadura civil-militar. Resistência.

\begin{abstract}
The news media has a fundamental role in our society: in addition to the production and circulation of information, and the reproduction of contemporary events, it is a subject in the construction of the present history and in the production and reconfiguration of memories. In this work, we analyze the production of memories, by the so-called big media, about the Brazilian civil-military dictatorship. Through the theoretical framework of the French line of Discourse Analysis, based on the works of Michel Pêcheux and his group, in dialogue with Michel Foucault and the New History, we analyze texts produced by the newspapers Estado de São Paulo and Folha de São Paulo and by the magazine Veja at times of debate about the possible revision of the Amnesty Law in 2010, and at the creation of the National Truth Commission in 2012. We thus see a reconfiguration in that production, which shifts from the official discourse and opens possibilities for the emergence of memories of resistance.
\end{abstract}

Keywords: Memories. Media. Civil-Military Dictatorship. Resistance.

\footnotetext{
'Docente da Universidade Federal de Uberlândia (UFU), Brasil. E-mail: israeldesa@gmail.com.
} 
EID\&A - Revista Eletrônica de Estudos Integrados em Discurso e Argumentação, Ilhéus, n. 16 esp. "Discurso e argumentação na política latino-americana, set.2018.

\section{Introdução}

Embora se constituam como dois campos discursivos apartados, o político e o midiático, nos últimos tempos, confundem-se e, muitas vezes, se sobrepõem, de tal modo que é hoje quase impossível pensar política - e até mesmo a construção da história e as diversas formas de circulação de textos e discursos na sociedade - sem recorrer a uma observação e análise do discurso midiático. É também muitas vezes pelas diferentes formas do discurso midiático que o discurso político ganha corpo e circula; além disso, há ainda certa ordenação imposta pela mídia ao discurso político: na mídia, as narrativas instituem verdades de um dizer político também verdadeiro, porém os silenciamentos, apagamentos e reconstruções fazem entrever que tais verdades não são jamais únicas.

O período de ditadura militar no Brasil, entre os anos de 1964 e 1985, fortaleceu o aparato repressivo, desde o seu início, também, e fundamentalmente, por meio do controle e censura aos diversos meios de comunicação, em especial àqueles considerados minimamente progressistas, cujas vozes faziam emergir as críticas ao regime e, em alguns casos, suscitar a resistência. Em contrapartida, a grande mídia, reiterando um discurso oficial, instituía a história e construía uma visão política pelos mesmos olhos da ditadura, que possibilitaria, posteriormente, a produção de uma única memória, oficializada e "verdadeira", e constituída por um discurso também quase único - a resistência armada, por sua vez, não tinha voz alguma nos mais diversos meios de comunicação.

Com a abertura política e o posterior, e lento, processo de redemocratização, instaurado em meados de 1985, a memória do período, ainda oficializada e monológica, se consolidava no silêncio e na opacidade, e as memórias da resistência se deslocavam da clandestinidade própria do período repressor para a mais clara marginalidade democrática (de alguns poucos veículos de também pouca circulação nacional); pouco se falava e, portanto, circulava sobre os acontecimentos daquele período obscuro da história brasileira, a não ser uma história hiperbolizada de ordem e progresso. Isto começa a sofrer alguma transformação apenas no início do século XXI, quando alguns acontecimentos, sobretudo político-institucionais, deram visibilidade àquele período e, de modo particular, a dois aspectos importantes daquele momento: a própria resistência armada à ditadura militar (sua ação, 
EID\&A - Revista Eletrônica de Estudos Integrados em Discurso e Argumentação, Ilhéus, n. 16 esp. "Discurso e argumentação na política latino-americana, set.2018.

seus personagens, suas reivindicações etc.) e a imprensa que pela linguagem resistia à ordem, à imposição dos costumes e à repressão.

É, então, sobre memórias da ditadura, em especial aquelas que "revelam" a resistência, que emergem neste momento da história brasileira, mais de duas décadas após o fim da ditadura militar, e têm na mídia um aspecto de sua produção, que nos debruçamos neste breve trabalho. Tomaremos, na constituição de um pequeno corpus de referência, alguns textos produzidos em revista e jornais de grande circulação nacional no ano de $2012^{1}$, período no qual se estabeleceu os trabalhos regulares da Comissão Nacional da Verdade (CNV), que nos serve como um acontecimento de base, e novas memórias daquele período deslocam-se da opacidade à visibilidade.

Antes, contudo, de entrarmos efetivamente na descrição e análise do corpus, propomos uma breve, porém importante, discussão a respeito dos discursos político e midiático, tomados evidentemente como dois campos, uma vez que os consideramos em relação, mas calcados por especificidades que os apartam, de modo que não podem ser confundidos e tomados um pelo outro. Essa reflexão nos parece fundamental na medida em que muitos trabalhos atuais tratam dessa amarra, confundindo, às vezes, um com o outro; além disso, essa discussão nos serve como uma espécie de fundamentação teórica para as análises que aparecem na sequência, uma vez que é preciso compreender tais características para o processo analítico, bem como suas relações intrínsecas com os conceitos fundamentais da Análise do discurso dos quais nos apropriamos para efeito de análise.

1. Política, mídia e produção de memórias: entrecruzamentos e diferenças entre campos discursivos

Um aspecto que é importante ser discutido no interior da Análise do discurso - e que é também a base de sustentação deste trabalho - é a diferença entre discurso político e discurso midiático, bem como seus entrecruzamentos. Essa discussão se faz necessária em função de inúmeras

\footnotetext{
${ }^{1}$ Para este trabalho, selecionamos para análise textos produzidos pela revista Veja e pelos jornais Folha de S. Paulo e Estado de S. Paulo, veículos de grande circulação nacional. Daquela revista, pesquisamos nove edições, publicadas entre os dias 18 de abril e 20 de junho, sendo elas a edição publicada imediatamente após a instalação da Comissão, em 23 de maio de 2012, as quatro anteriores a ela, e as quatro posteriores; quanto aos jornais, buscamos textos sobre a CVN - e, num âmbito global, sobre a ditadura - em 13 edições de cada, tomando como referência a edição publicada no dia da instalação da Comissão, em 16 de maio de 2012, as cinco edições anteriores a ela, e as sete posteriores.
} 
EID\&A - Revista Eletrônica de Estudos Integrados em Discurso e Argumentação, Ilhéus, n. 16 esp. "Discurso e argumentação na política latino-americana, set.2018.

confusões que aparecem, especialmente, em trabalhos que tratam da política (e de seus dizeres) por meio da produção e circulação midiática, principalmente pelo jornalismo. Nesse sentido, ainda que ambos tenham relação, como está claro, dissociam-se em alguns pontos, entre eles, os sujeitos da enunciação, o gênero do discurso e a relação que se estabelece com a história e a memória.

A mídia tem papel fundamental na constituição e circulação de discursos políticos, e isso se torna mais verdadeiro se considerarmos suas diversas formas e seus mais variados meios. É por meio dela - dos jornais impressos, revistas, da televisão, das plataformas virtuais, da publicidade etc. - que a política e o discurso político ganham visibilidade e, por isso, circulam de modo mais amplo, atingindo um público maior e que muitas vezes não teria outro acesso à política a não ser pela mídia. Essa forma de manifestação da política, contudo, torna-se problemática quando se observam os recortes nos dizeres, as transformações e os imbricamentos que se estabelecem na própria voz do sujeito da mídia, uma vez que, como aponta Navarro (2003, p. 113), "no discurso jornalístico, o lugar midiático articula-se também com o saber e o poder. $O$ jornalista não pode falar como quiser, pois tem de se submeter a certas regras internas e externas da instituição midiática", o que propicia o deslocamento do real histórico (e político) na construção de novos e diferentes sentidos. Ora, em que medida, então, a separação entre um e outro se efetiva?

Primeiramente, é preciso pensar a constituição dos sujeitos, portanto na relação entre formulação dos enunciados e produção. No discurso político, o sujeito constitui-se, antes, como agente da prática política (institucional ou não) e sua formulação articula-se claramente a essa prática, alinhando-se às demandas sócio-histórico-políticas. No discurso midiático, por sua vez, o sujeito efetiva-se numa suposta reprodução do real (histórico, político, social, cultural etc.) e, desse modo, faz entrever sua prática associada às outras práticas, uma vez que ela se vale, e mais, necessita delas para ter existência. É nesse ponto, portanto, que o discurso midiático, e o jornalismo de modo mais característico, se estabelece como um mecanismo fundamental de interpretação e reordenamento das práticas sociais, de construção da história do tempo presente e de produção de memórias: "Tendo em vista que o real não se deixa apreender diretamente, o verossímil no jornalismo encontra-se 
EID\&A - Revista Eletrônica de Estudos Integrados em Discurso e Argumentação, Ilhéus, n. 16 esp. "Discurso e argumentação na política latino-americana, set.2018.

em relação direta com o efeito de real construído discursivamente" (NAVARRO, 2010, p. 85).

Segundo Mariani (1993, p. 33), "em suma, o discurso jornalístico (assim como qualquer outra prática discursiva) integra uma sociedade, sua história. Mas ele também é história, ou melhor, ele também está entranhado de historicidade". Nesse aspecto, a mídia, de modo geral, e o discurso jornalístico, de modo particular, quando na intersecção com a política, têm papel fundamental na construção da história e na produção de memórias. Nessa relação, a mídia, carregada de sua historicidade e jamais afastada de suas posições ideológicas (e de sujeito discursivo), faz circular sentidos próprios e distintos daqueles do discurso político. E é justamente isso que nos interessa neste trabalho, uma vez que buscaremos analisar a produção e circulação de discursos sobre a ditadura militar brasileira em três veículos jornalísticos, o que possibilita a constituição de memórias do período e, em especial, da resistência ao regime militar - e nesse aspecto, o discurso midiático desloca-se e, portanto, lhe é conferido também um status de discurso histórico.

Um segundo aspecto importante, e que deve ser destacado, é que tanto o discurso político quanto o discurso midiático valem-se de gêneros que thes são mais característicos, ainda que a inter-relação entre eles possa se efetivar (e de fato se efetiva). Os gêneros do discurso, constituídos sóciohistoricamente, estão fortemente articulados aos mecanismos de produção e circulação dos discursos, bem como às suas condições histórico-ideológicas. Os gêneros são definidos no interior das formações discursivas, que buscam na sua estrutura composicional, na marca de seu tema, uma possibilidade para aquilo que se "quer" dizer, para o seu conteúdo. Desse modo, é definido ao mesmo tempo o "como transmitir" aquilo que se quer dizer e sua possibilidade de circulação, seu alcance na cadeia social.

É sabido que, cada vez mais, há um deslocamento das formas de produção e circulação dos discursos políticos para a mídia (os programas eleitorais gratuitos, as redes sociais na internet, os blogs etc.), mas, neste caso, são aqueles que se valem dessa para fazer circular seus sentidos e atingir a todos em seus lugares mais privados; há, nesse aspecto, um deslocamento dos gêneros doutrinários, o que permite novas formas de circulação dos sentidos. A mídia, em si, caracteriza-se na articulação entre o sujeito discursivo (para nós o jornalista) e a sua função noticiosa/informativa, o que lhe confere 
EID\&A - Revista Eletrônica de Estudos Integrados em Discurso e Argumentação, Ilhéus, n. 16 esp. "Discurso e argumentação na política latino-americana, set.2018.

o caráter da (re)produção e da articulação com todos os demais campos da esfera social. Na mídia e no jornalismo, a sociedade, a história, a política, a cultura são recortadas, reorganizadas, de modo que um acontecimento, eivado de novos sentidos, se produz.

A produção, então, de um acontecimento discursivo, na mídia, passa, estruturado na fragmentação e fluidez dos discursos na contemporaneidade, pela repetibilidade de certos discursos (o aparecimento de determinados enunciados; enunciados que se repetem), que indica que seus aparecimentos não são aleatórios; são, portanto, recortados do real. Ainda, na apropriação da política e da própria história pelos olhos da mídia e, do jornalismo em especial, constituem-se recortes que dão ordenamentos à produção de sentidos:

O objeto da prática midiática é também o presente, transmutado em acontecimento jornalístico e, muitas vezes, em espetáculo. A mídia não somente transforma o presente em acontecimento jornalístico, como também lhe confere um estatuto histórico. Desse modo, a sociedade assiste à história do tempo presente sendo construída, no interior dos aparelhos de comunicação de massa, sob a tirania do acontecimento. O lugar, por excelência, de produção do acontecimento não é mais o do discurso da história, mas sim o da mídia [...] (BARBOSA, 2003, p. 115-116).

Nesse ponto, Gregolin afirma que:

[...] a mídia produz sentido por meio de um insistente retorno de figuras, de sínteses-narrativas, de representação que constituem o imaginário social. Fazendo circular essas figuras, ela constrói uma 'história do presente', simulando acontecimentos-em-curso que vêm eivados de signos do passado (2003, p. 96).

A mídia, pela função conferida ao jornalismo, é atuante, desse modo, pela produção sentidos políticos e, em grande medida, históricos. É aí então que se faz presente o seu terceiro aspecto, qual seja, a relação que a mídia estabelece com a história e a memória.

Atentando-nos para nossa proposta de análise neste trabalho, é perceptível um duplo aspecto: a midiatização da história do período militar (SÁ, 2017) e também da resistência (verificada no processo de abertura política e de transição com a redemocratização, que se pode ver no deslocamento da clandestinidade para a marginalidade) e a produção de memórias da ditadura pela mídia (que se configura nos trinta anos de suposta democracia). Na sequência, nos debruçaremos sobre enunciados produzidos por veículos jornalísticos de grande circulação nacional com o objetivo de tentar compreender a produção de memórias daquele período na 
EID\&A - Revista Eletrônica de Estudos Integrados em Discurso e Argumentação, Ilhéus, n. 16 esp. "Discurso e argumentação na política latino-americana, set.2018.

contemporaneidade (o segundo aspecto daquela duplicidade), particularmente no século $\mathrm{XXI}$, e em especial memórias da resistência ao regime militar.

2. O papel da mídia na produção de memórias e na construção de sentidos históricos

O discurso político, quando retomado pela mídia nesse processo de abertura política e consequente redemocratização do país, ganha a condição de espetáculo. Há, dessa forma, toda uma reestruturação no modo de tratamento da política, não apenas uma redefinição dessa temática pela mídia jornalística no processo de espetacularização, mas também suas manifestações, as formas de pronunciamento, pelos próprios sujeitos políticos: "umas das conseqüências mais marcantes do desenvolvimento de uma tecnologia da comunicação política terá sido a de modificar a relação entre enunciação do discurso e espetáculo do corpo falante, em proveito deste último" (COURTINE, 2003, p. 25).

Por meio do apelo, da espetacularização, a mídia tenta se fundir com a sociedade e se aproximar dos desejos e anseios do espectador. Piovezani Filho (2003) acrescenta que "com a dissolução da ditadura militar, a 'espetacularização' da política brasileira foi um meio encontrado para reverter ou, ao menos, mitigar o desinteresse, o descrédito e a incredulidade frente ao discurso político" (p. 54). De todo modo, essa espetacularização, que se estabeleceu e se consolidou de fato no pós-ditadura, já vinha se desenhando nos anos finais da ditadura militar. Ela começou a se dar - pequenos indícios na mídia a partir do momento em que o regime começa a se abrir e a necessidade de trazer a sociedade para os assuntos políticos.

A produção da história hoje, que está intrinsecamente permeada pela consolidação de memórias, passa, sem dúvida, pelos jogos que se estabelecem na mídia. Uma memória do período de ditadura militar no Brasil não é diferente e vem marcada pela visibilidade que conjuga opacidade e silenciamento, regulação e silêncio - como mostra Zoppi-Fontana (2011, p. 169), "a democracia tem a ver com a produção de um visível, e o quanto a produção desse visível depende de invisíveis que ainda nos habitam”. É justamente nesse ponto que o jogo entre memórias possíveis do período de ditadura militar brasileira se estabelece, configurando relações de opacidade e visibilidade entre vozes e sujeitos históricos. 
EID\&A - Revista Eletrônica de Estudos Integrados em Discurso e Argumentação, Ilhéus, n. 16 esp. "Discurso e argumentação na política latino-americana, set.2018.

O aparecimento de um discurso de retomada no interior da mídia não cria ainda um regime de visibilidade e muito menos provoca uma hipervisibilidade que sustente o tema, ao contrário do que ocorreu Argentina, por exemplo, cuja mídia de massa, em especial a televisiva, trouxe o julgamento (e a condenação) de agentes políticos da ditadura e provocou uma rede de visibilidade que sustenta uma hipervisibilidade (ZOPPI-FONTANA, 2011). Há, portanto, relação com o que afirma Pêcheux (1999), de que há uma "fragilidade, uma tensão contraditória no processo de inscrição do acontecimento no espaço da memória" (p. 50), pois há o acontecimento que escapa à memória, que não chega a se inscrever, e há o acontecimento que é absorvido na memória, como se não tivesse ocorrido - a mídia acentua, então, a visibilidade que dá margem para uma compreensão do todo, que atesta uma característica de produção do real, mas que na verdade é apenas "efeito de", que marca a opacidade e acentua a relação do visível com o invisível, da produção de sentidos com o silêncio.

Na sequência, nos debruçamos sobre textos produzidos em três veículos de grande circulação nacional - os jornais O Estado de S. Paulo e Folha de S. Paulo e a revista Veja - publicados no momento imediatamente posterior à constituição da Comissão Nacional da Verdade, no primeiro semestre de 2012. Para este trabalho, observaremos as manchetes de textos (notícias, reportagens, editoriais e textos de opinião, entrevistas etc.) que trataram do período ditatorial e/ou de algum acontecimento decorrente ou que tenha relação com aquele momento da história brasileira.

\section{Na Veja não se vê a ditadura}

Quando se pensa na consolidação de um possível 'dizer a ditadura', na fixação de um limite de dizibilidade (FOUCAULT, 2010) no qual é possível dizer o passado sem a sombra viva da interdição - e seja para dizê-lo apenas olhando para trás, seja olhando também para o presente e o futuro -, pensase, também, em liberdade total. Ora, isso, sabemos, não é possível, uma vez que a interdição é um mecanismo de regulação permanente do discurso e, por isso, faz com que 'nem tudo possa ser dito por todos em qualquer lugar' (FOUCAULT, 2004). A liberdade total e irrestrita, portanto, é ilusória e as possibilidades de dizer mudam não apenas conforme o tempo e o espaço como também de acordo com as diferentes formações discursivas. 
EID\&A - Revista Eletrônica de Estudos Integrados em Discurso e Argumentação, Ilhéus, n. 16 esp. "Discurso e argumentação na política latino-americana, set.2018.

Sem dúvida, foi criada no século XXI, especialmente a partir de sua segunda década, a possibilidade real de emergência de dizeres ${ }^{2}$ - de certa forma, combativos - sobre a ditadura militar brasileira. Isso a partir, especialmente, de acontecimentos-base, de dispositivos de produção discursiva, como a possibilidade de revisão da Lei de Anistia ${ }^{3}$ e a instauração da Comissão Nacional da Verdade. Contudo, esses dizeres emergem e circulam com intensidades diferentes também de acordo com seus espaços de produção e com as formações discursivas, que apresentam diferentes mecanismos de regulação. E é por isso que voltamos nosso olhar primeiramente para a revista Veja, semanário explicitamente alinhado ao conservadorismo e às propostas da direita econômica (do neoliberalismo), que no momento do primeiro acontecimento-base, o processo de revisão da Lei de Anistia, não deu qualquer destaque a ele, e no segundo publicou apenas dois textos e um quadro comparativo (uma espécie de ilustração à reportagem principal), em uma mesma edição, no período recortado.

É importante, contudo, que também nos desloquemos - sem deixar de observá-los, mas não os tomando como prioridade - dos dados quantitativos para analisar, naquilo que emergiu, a produção discursiva e seus efeitos de sentido. São dois textos (um editorial e uma reportagem) nesta edição que remetem à instauração da Comissão pelo governo federal e suas manchetes são compostas pelos seguintes enunciados:

(1) A verdade vos libertará

(2) O direito à verdade

O primeiro enunciado é a manchete para um editorial (na revista, sua Carta ao leitor) que discute dois fatos ligados ao governo federal: a instalação da Comissão Nacional da Verdade e a aprovação da Lei de Acesso à Informação - dois fatos que se encontravam tendo como pano de fundo um

\footnotetext{
${ }^{2}$ É preciso ressaltar, sem dúvida, que a transformação conservadora e retrógrada promovida desde o processo de impeachment (ora, golpe!) da ex-presidenta Dilma Rousseff promoveu retrocessos também nesse "dizer a ditadura", uma vez que trabalhos importantes de recuperação da memória daquele período foram marginalizados e/ou abandonados e um discurso pró-militares ganhou visibilidade em manifestações de rua ou, mesmo, no Congresso durante a forte crise institucional brasileira.

${ }^{3}$ No ano de 2010, o Supremo Tribunal Federal (STF) julgou um pedido, protocolado pela Ordem dos Advogados do Brasil (OAB), de revisão da Lei de Anistia. Ainda que a demanda tenha sido derrotada, o acontecimento do julgamento foi bastante importante nesse processo de produção de memórias daquele período, em especial de memórias da resistência, na medida em que diversos atores políticos foram mobilizados para comentar o processo jurídico e acontecimentos silenciados foram recuperados pela mídia como forma de mostrar a atuação da repressão aos movimentos de esquerda.
} 
EID\&A - Revista Eletrônica de Estudos Integrados em Discurso e Argumentação, Ilhéus, n. 16 esp. "Discurso e argumentação na política latino-americana, set.2018.

tema comum, a verdade, mas em extensões e amplitudes diferentes: a verdade que abrange os períodos ditatoriais (desde o período governado por Getúlio Vargas até o fim da ditadura militar, embora o foco se dê neste segundo período) e a verdade das informações administrativas do Estado (um tema ligado à transparência administrativa).

O enunciado (1), nesse sentido, apresenta uma dupla implicação: i) luz: a clarificação dos fatos (a verdade das ditaduras e o acesso a documentos do passado e do presente) liberta (e, até mesmo, salva) os homens dos ecos do passado repressivo (recordar para não repetir; não se trata, portanto, de punir) e dos desvios administrativos (a transparência do Estado e de seus órgãos); ii) opacidade: a 'simples' emergência da verdade, no caso da ditadura militar, o esclarecimento dos fatos, faz com que não sejam necessários o julgamento e a condenação de agentes da repressão, porque a verdade já é ela um 'acerto de contas' com o passado - há, nesse caso, uma espécie de continuidade discursiva, uma vez que retoma e/ou reitera enunciados que circularam na época do processo de revisão da Lei de Anistia, dois anos antes deste acontecimento-base.

A verdade é tomada como um 'dado a priori', que se manifesta também em (2) como um 'direito': o direito à verdade. Contudo, a partir desses enunciados alguns questionamentos se impõem e marcam a opacidade de ambos: a quem e de que a verdade libertará? Qual é essa verdade que liberta? O esclarecimento do passado (a verdade) é suficiente para a liberdade no presente? Quem tem direito à verdade, é um direito universal? Qual é essa verdade que é um direito? A questão, olhando por esse viés, nos parece mais filosófica que histórica (a ditadura) e política (a ditadura, mas também o acesso a informações do Estado).

Nesse aspecto, é importante observar, levando sempre em conta os enunciados (1) e (2), pela reiteração do vocábulo, que a verdade está acima da ditadura, enquanto aspecto temático e possíveis inscrições em diferentes formações discursivas: ora, apenas pela leitura dos enunciados que compõem as manchetes não é possível identificar que será também tratado da criação da Comissão Nacional da Verdade e, muito menos, que essa verdade tem relação com acontecimentos ocorridos durante o período de ditadura militar no Brasil. Portanto, a discussão em torno da verdade contingente (a verdade como direito) carrega, em si, silêncios sobre o debate que se queria no momento, a verdade do passado, o que é preciso saber sobre a ditadura 
EID\&A - Revista Eletrônica de Estudos Integrados em Discurso e Argumentação, Ilhéus, n. 16 esp. "Discurso e argumentação na política latino-americana, set.2018.

militar brasileira e que ainda naquele momento não se sabia, as relações efetivas de militares, do Estado, com a repressão política.

Em ambos os enunciados, assim observamos, a relação é mais forte com o presente do que com o passado, pois o foco, como vimos, está na verdade, e não na ditadura. Desse modo, há um desvio, aqui, na produção da memória da ditadura militar brasileira, ou melhor, a produção dessa memória, se tomássemos como parâmetro apenas publicações da revista Veja, se dá na opacidade do discurso que emerge em torno da verdade: configura-se maior grau de relevância à verdade em detrimento da ditadura. Não é preciso que se mostre claramente qual é essa verdade, a quem ela serve e quem a tem como direito, porque, na opacidade discursiva, ela é ampla, universal, ela é única. Importa menos 'dizer a ditadura' que 'revelar a verdade', seja ela qual for e sobre o que for - e nesse ponto é interessante observar que o quadro comparativo que ilustra a reportagem tem como título "Muitas comissões, muitas verdades".

A memória da ditadura, desse modo, vai se formando pelo não dizer completamente. Se a instauração da Comissão Nacional da Verdade possibilitou que mais se falasse sobre a ditadura - e sempre lembramos que no processo de revisão da Lei de Anistia nada foi publicado naquela revista -, esse dizer era ainda opaco. Por outro lado, esse acontecimento-base gerou na grande mídia um debate mais amplo sobre diversos aspectos, levantados a partir dele. Nos diários paulistas, Folha de S. Paulo (FSP) e Estado de S. Paulo $(E S P)$, naquele período, borbulharam reportagens e textos analíticos.

\section{Visibilidade '(im)parcial’}

Os diários paulistas, em contraposição à revista Veja, deram visibilidade ao acontecimento por meio de manchetes em Capa e de inúmeros textos de diferentes gêneros ${ }^{4}$, com foco principal na instauração da Comissão, mas também no 'seu entorno'. Num primeiro olhar, então, observa-se que o foco do debate se deu sobre três aspectos - mas em diferentes níveis, de que trataremos mais adiante -, quais sejam: i) a instauração da Comissão Nacional

\footnotetext{
${ }^{4}$ No período analisado, de 11 a 23 de maio de 2012, o jornal Folha de S. Paulo repercutiu amplamente o tema: 43 manchetes (sendo nove na capa do jornal, mas nenhuma delas funcionando como chamada principal) e 34 textos, divididos entre 22 reportagens, oito artigos de opinião, dois editoriais, um artigo analítico e uma nota; nesse mesmo período, o diário Estado de S. Paulo também repercutiu o tema de forma intensa: 30 manchetes (sendo cinco de capa, uma delas funcionando como chamada principal) e 25 textos, divididos entre 15 reportagens, quatro artigos analíticos, dois artigos de opinião, duas notas, um editorial e uma entrevista.
} 
EID\&A - Revista Eletrônica de Estudos Integrados em Discurso e Argumentação, Ilhéus, n. 16 esp. "Discurso e argumentação na política latino-americana, set.2018.

da Verdade, a atuação de seus membros na vida política e social e as generalidades sobre seu campo de atuação; ii) o imbróglio em torno das investigações: se verificar ações apenas de agentes do Estado ou as ações tanto de agentes do Estado como também da resistência armada; iii) a memória do período de ditadura militar no Brasil, porque tomando outros aspectos daquele período, deslocando-se do acontecimento-base para um debate mais profundo (a revisão da Lei de Anistia, a abertura de documentos das forças armadas, a punição a agentes da repressão, as reações das Forças Armadas frente aos debates sobre a ditadura etc.). Nota-se que os pontos um e dois estão interligados, uma vez que a base é ainda a Comissão, contudo os separamos pelo fato de que um é a própria constituição do grupo, outro é a polêmica em decorrência de sua formação e de sua atuação, que de certo modo gerou um embate entre Forças Armadas e governo. Por outro lado, o terceiro ponto é um deslocamento acabado dos demais, porque trata do período sem recorrer diretamente à formação da Comissão, ou, de outro modo, parte dos trabalhos que seriam atribuídos à Comissão para uma reflexão mais ampla sobre o período ou para uma especificidade da ditadura.

Em seus textos, tanto a FSP como o ESP apelam mais para os enunciados que chamamos, aqui, de 'informativos' em suas manchetes, muitas vezes, inclusive, com a utilização dos discursos indireto e direto. Esse tipo de enunciado informa o leitor sobre os acontecimentos, pautando-se numa espécie de narrativa noticiosa, instaurando um título genérico para o texto da notícia.

Observemos, primeiramente, três exemplos de manchetes para reportagens retiradas de cada jornal:

(3) Militares aprovam escolhidos para a Comissão da Verdade (FSP, 12 maio 2012)

(4) Acordo prevê que esquerda será investigada, afirma Jobim (FSP, Capa, 16 maio 2012)

(5) 'Comissão da Verdade não deve ter ódio nem perdão', afirma Dilma (FSP, Capa, 17 maio 2012)

(6) Dilma escolhe membros da Comissão da Verdade (ESP, Capa, 11 maio 2012)

(7) Comissão da Verdade será rigorosa, mas sem revanche, dizem membros (ESP, 18 maio 2012)

(8) Comissão da Verdade agirá 'doa a quem doer', diz Dipp (ESP, Capa, 12 maio 2012) 
EID\&A - Revista Eletrônica de Estudos Integrados em Discurso e Argumentação, Ilhéus, n. 16 esp. "Discurso e argumentação na política latino-americana, set.2018.

De modo distinto dos enunciados encontrados na revista Veja e analisados anteriormente, as manchetes desses jornais partem de afirmativas diretas, como quando ocorreu a repercussão do processo de revisão da Lei de Anistia, corroborando o caráter informativo. O primeiro enunciado de Veja - A verdade vos libertará - é título para um editorial da revista, que supostamente justifica seu caráter vago, cujos sentidos se completam pela reflexão analítica do texto (o editorial em si). $\mathrm{O}$ segundo enunciado - $\mathrm{O}$ direito à verdade -, por sua vez, é título para sua reportagem sobre a instauração da Comissão Nacional da Verdade, no entanto, ainda assim esse título mantém caráter vago, incompleto, ou, antes, aberto, próprio de uma reflexão filosófica ou sociológica, e que em muito se distingue das afirmativas jornalísticas, que estão mais evidentes nos exemplos que apresentamos da Folha de S. Paulo e do Estado de S. Paulo.

A opacidade que se revela nos enunciados introdutórios produzidos pela revista, que inscrevem sentidos de silenciamento sobre a ditadura militar brasileira, é contraposta, então, pela visibilidade (e pela explicitação) dada pelos enunciados aos acontecimentos tratados nos diários paulistas. Nota-se, nesse aspecto, que os seis exemplos apresentados acima (de 3 a 8 ) são enunciados que mostram, ou dão uma ideia, ao leitor aquilo que será tratado no texto da reportagem. O leitor, aqui, a partir desses seis enunciados, consegue perceber que o tópico central (para nós, o acontecimento-base) é a Comissão Nacional da Verdade, sublinhando, cada qual, diferentes especificidades da Comissão e de seu trabalho.

Essa visibilidade se sustenta ainda mais quando observamos que, em grau numérico menor - mais uma vez recorremos a aspectos quantitativos para sustentar nosso olhar para a circulação -, mas bastante relevante, muitos textos que aparecem têm como foco a ditadura militar brasileira, sem diretamente tratar da Comissão e de seus trabalhos. Esse é um fator que corrobora nossas análises que mostram a instauração da Comissão como um acontecimento-base - ou, se preferir, um dispositivo - que fundamenta um limite de dizibilidade e aciona dizeres que vão além do próprio acontecimento, instados na e pela memória discursiva, sustentando essa memória que se produz da ditadura.

Vejamos, então, mais três exemplos retirados de cada um dos jornais que, agora, reforçam os três aspectos que elencamos acima: 
EID\&A - Revista Eletrônica de Estudos Integrados em Discurso e Argumentação, Ilhéus, n. 16 esp. "Discurso e argumentação na política latino-americana, set.2018.

(9) Dilma indica grupo que vai investigar crimes na ditadura (FSP, Capa, 11 maio 2012)

(10) Advogada defende que comissão não investigue esquerda (FSP, Capa, 15 maio 2012)

(11) Dois personagens à procura de uma história (FSP, Capa, 20 maio 2012)

(12) Dilma escolhe membros da Comissão da Verdade (ESP, Capa, 11 maio 2012)

(13) Comissão da Verdade não vai investigar militantes (ESP, Capa, 15 maio 2012)

(14) Revisão da Lei de Anistia depende da opinião pública (ESP, 17 maio 2012)

No jornal Estado de S. Paulo, foram três manchetes para reportagens que tratavam de outros temas ligados à ditadura que não a Comissão da Verdade (como no exemplo 14), além de dois artigos de opinião, e três manchetes para reportagem (exemplo 13) e uma para entrevista que tratam do debate entre investigar apenas as Forças Armadas ou também a esquerda. Na Folha de S. Paulo, 11 manchetes para reportagem (exemplo 11) e três para artigos de opinião informaram temas da ditadura não ligados à Comissão, além disso, sete manchetes de reportagem (exemplo 10) e uma de artigo de opinião que apontam a discussão entre julgar apenas as Forças Armadas ou também a esquerda.

Se aparentemente o recurso ao texto de informação - com os enunciados informativos que mencionamos - apaga reflexões tanto sobre o passado quanto sobre o presente e o futuro, uma vez que trata apenas do fato em si, ele também é base para a produção da memória do período, porque do acontecimento-base emerge a necessidade de informações sobre outros fatos a ele atrelados, ou correlacionados. Notamos que a maior parte das reportagens é sobre a Comissão Nacional da Verdade, sua forma de trabalhar, seus mecanismos de investigação e seu objetivo. Contudo, carece de uma abordagem mais ampla, que contemple análises do passado ditatorial, de traços no presente e de reflexões sobre o futuro. Essa abordagem, de certa forma, se dá pelas reportagens que aparecem, em menor medida, mas, como apontamos, em grau relevante, paralelamente à constituição da Comissão e tratam de aspectos outros daquele período ou a ele associados. Também essas reportagens, e suas manchetes, exercem o papel de informar o leitor sobre outros acontecimentos da ou ligado à ditadura - como, por exemplo, uma possível revisão da Lei de Anistia (14). 
EID\&A - Revista Eletrônica de Estudos Integrados em Discurso e Argumentação, Ilhéus, n. 16 esp. "Discurso e argumentação na política latino-americana, set.2018.

No mesmo sentido, mas de modo distinto, os editoriais, os artigos analíticos e de opinião também ampliam o debate e suas manchetes assemelham-se àquelas da revista Veja. Vejamos alguns exemplos.

(15) A verdade que dói (FSP, Eliane Cantanhêde, 13 maio 2012)

(16) Mais luz (FSP, Editorial, 16 maio 2012)

(17) O cavalo e o camelo (FSP, Carlos Heitor Cony, 22 maio 2012)

(18) Lei do silêncio (ESP, general Romulo Bini Pereira, 12 maio 2012)

(19) Lição da memória (ESP, Dora Kramer, 18 maio 2012)

Como se vê, pelos exemplos de 15 a 19, a ampliação do debate - fator que demonstra a fixação de um limite claro de dizibilidade em torno da ditadura - é marcada por comentários que partem do acontecimento-base e vão para uma discussão mais profunda: a verdade (como em Veja), a memória, o silêncio (e o dizer), a história etc. $O$ uso de enunciados metafóricos sustenta o caráter analítico e reflexivo dos textos, que não querem focar apenas o acontecimento. Dessa forma, produz-se uma memória cujo trânsito se dá entre passado e futuro (sobretudo enunciados 15, 16 e 17), distinguindo-se, também, do texto propriamente jornalístico (a reportagem, as notas, as matérias etc.), cujo foco é quase sempre o fato, o próprio acontecimento.

A memória da ditadura, então, se fortalece, também pela mídia, pela ampliação dos limites de dizibilidade. A emergência de acontecimentos-base (como a revisão da Lei de Anistia e a instauração da Comissão da Verdade) são reflexos de uma transição, ou de um movimento, nos regimes de discursividade, instaurando, também, uma nova ordem do discurso. Nesse ponto, as memórias que se instauram são, antes, da resistência, na medida em que promovem um deslocamento da memória e da história oficial, escritas pelo próprio regime (e seus agentes políticos na democracia) e proporcionam uma reflexão tanto sobre o passado repressivo quanto sobre o presente e o futuro do Brasil.

\section{Considerações finais}

Neste trabalho buscamos tratar do papel da mídia na produção de sentidos e memórias da ditadura militar brasileira, em especial sentidos e memórias que emergem em torno da resistência à ditadura e/ou de aspectos que propiciaram um “dizer a ditadura militar brasileira”. Nesse sentido, como 
EID\&A - Revista Eletrônica de Estudos Integrados em Discurso e Argumentação, Ilhéus, n. 16 esp. "Discurso e argumentação na política latino-americana, set.2018.

recorte metodológico, definimos um acontecimento-base, de grande visibilidade, a criação e instituição da Comissão Nacional da Verdade pelo governo da então presidenta Dilma Rousseff, em 2012, e, a partir dele, levantamos e selecionamos textos publicados em jornais e revistas de grande circulação nacional em período imediatamente anterior e posterior ao início dos trabalhos da CNV.

Durante o processo de seleção dos textos e, posteriormente, de descrição e análise dos enunciados, bem como, especialmente, da fundamentação teórica, observamos uma necessidade pungente de discutir sobre as proximidades e distanciamentos dos campos discursivos político e midiático. Isto se deu, em grande medida, pelo fato de muitos trabalhos tomarem um pelo outro, ou melhor, pelo fato de muitos trabalhos acreditarem tratar do discurso político quando, na verdade, tratam do discurso da mídia sobre e em torno da política. Por ser este o nosso objeto de análise, a mídia e seu tratamento da política (bem como da história brasileira), julgamos produtiva esta reflexão e conseguimos dar um passo na superação dessa problemática.

Nossas análises, por fim, mostraram um deslocamento da inscrição de memória da ditadura militar brasileira pela mídia, do discurso oficial (e, portanto, da história também oficial) para a inscrição da resistência, por meio de outras memórias (e verdades) possíveis. Com isso, timidamente, num processo lento de três décadas, um "dizer a ditadura" foi se configurando e se fortaleceu nos primeiros 15 anos do século XXI. As transformações recentes na história política brasileira, com a deposição da ex-presidenta Dilma Rousseff, contudo, promoveram, como era de se esperar, um refreamento e, certamente, um retrocesso nas políticas de memória, fazendo com que apenas dizer a ditadura, hoje, configure-se como um ato forte de resistência política.

\section{Fontes}

FOLHA DE SÃO PAULO, ano 92, n. 30.354, edição de 11 maio 2012, 2012.

FOLHA DE SÃO PAULO, ano 92, n. 30.355, edição de 12 maio 2012, 2012.

FOLHA DE SÃO PAULO, ano 92, n. 30.356, edição de 13 maio 2012, 2012. 
EID\&A - Revista Eletrônica de Estudos Integrados em Discurso e Argumentação, Ilhéus, n. 16 esp. "Discurso e argumentação na política latino-americana, set.2018.

FOLHA DE SÃO PAULO, ano 92, n. 30.357, edição de 14 maio 2012, 2012. FOLHA DE SÃO PAULO, ano 92, n. 30.358, edição de 15 maio 2012, 2012. FOLHA DE SÃO PAULO, ano 92, n. 30.359, edição de 16 maio 2012, 2012. FOLHA DE SÃO PAULO, ano 92, n. 30.360, edição de 17 maio 2012, 2012. FOLHA DE SÃO PAULO, ano 92, n. 30.361, edição de 18 maio 2012, 2012. FOLHA DE SÃO PAULO, ano 92, n. 30.362, edição de 19 maio 2012, 2012. FOLHA DE SÃO PAULO, ano 92, n. 30.363, edição de 20 maio 2012, 2012. FOLHA DE SÃO PAULO, ano 92, n. 30.364, edição de 21 maio 2012, 2012. FOLHA DE SÃO PAULO, ano 92, n. 30.365, edição de 22 maio 2012, 2012. FOLHA DE SÃO PAULO, ano 92, n. 30.366, edição de 23 maio 2012, 2012. O ESTADO DE SÃO PAULO, ano 133, n. 43.305, edição de 11 maio 2012, 2012. O ESTADO DE SÃO PAULO, ano 133, n. 43.306, edição de 12 maio 2012, 2012. O ESTADO DE SÃO PAULO, ano 133, n. 43.307, edição de 13 maio 2012, 2012. O ESTADO DE SÃO PAULO, ano 133, n. 43.308, edição de 14 maio 2012, 2012. O ESTADO DE SÃO PAULO, ano 133, n. 43.310, edição de 15 maio 2012, 2012. O ESTADO DE SÃO PAULO, ano 133, n. 43.311, edição de 16 maio 2012, 2012. O ESTADO DE SÃO PAULO, ano 133, n. 43.312, edição de 17 maio 2012, 2012. O ESTADO DE SÃO PAULO, ano 133, n. 43.313, edição de 18 maio 2012, 2012. O ESTADO DE SÃO PAULO, ano 133, n. 43.314, edição de 19 maio 2012, 2012. O ESTADO DE SÃO PAULO, ano 133, n. 43.315, edição de 20 maio 2012, 2012. O ESTADO DE SÃO PAULO, ano 133, n. 43.316, edição de 21 maio 2012, 2012. O ESTADO DE SÃO PAULO, ano 133, n. 43.317, edição de 22 maio 2012, 2012. O ESTADO DE S. PAULO, ano 133, n. 43.318, edição de 23 maio 2012, 2012. VEJA, ano 45, n. 16, edição 2.265, de 18 abr. 2012, 2012. VEJA, ano 45, n. 17, edição 2.266, de 25 abr. 2012, 2012. VEJA, ano 45, n. 18, edição 2.267, de 2 maio 2012, 2012. 
EID\&A - Revista Eletrônica de Estudos Integrados em Discurso e Argumentação, Ilhéus, n. 16 esp. "Discurso e argumentação na política latino-americana, set.2018.

VEJA, ano 45, n. 19, edição 2.268, de 9 maio 2012, 2012.

VEJA, ano 45, n. 20, edição 2.269, de 16 maio 2012, 2012.

VEJA, ano 45, n. 21, edição 2.270, de 23 maio 2012, 2012.

VEJA, ano 45, n. 22, edição 2.271, de 30 maio 2012, 2012.

VEJA, ano 45, n. 23, edição 2.272, de 6 jun. 2012, 2012.

VEJA, ano 45, n. 24, edição 2.273, de 13 jun. 2012, 2012.

\section{Referências}

COURTINE, Jean-Jacques. Os deslizamentos do espetáculo político. Trad. Roberto LeiserBaronas e Fábio César Montanheiro. In: GREGOLIN, Maria do Rosário (Org.). Discurso e mídia: a cultura do espetáculo. São Carlos: Claraluz, 2003. p. 21-34.

FOUCAULT, Michel. A ordem do discurso. Trad. Laura Fraga de Almeida Sampaio. 11. ed. São Paulo: Loyola, 2004.

. Resposta a uma questão. In: MOTTA, Manoel Barros da. Michel Foucault: repensar a política. (Ditos \& Escritos VI). Trad. Ana Lúcia Paranhos Pessoa. Rio de Janeiro: Forense Universitária, 2010. p. 1-24.

GREGOLIN, Maria do Rosário. O acontecimento discursivo na mídia: metáfora de uma breve história do tempo. In: Discurso e mídia: a cultura do espetáculo. São Carlos: Claraluz, 2003. p. 95-110.

MARIANI, Bethania Sampaio Corrêa. Os primórdios da imprensa no Brasil (ou: de como o discurso jornalístico constrói memória). In: ORLANDI, Eni Puccinelli (Org.). Discurso fundador: a formação do país e a construção da identidade nacional. Campinas: Pontes, 1993. p. 31-42.

NAVARRO, Pedro Luis. O papel da imagem e da memória na escrita jornalística da história do tempo presente. In: GREGOLIN, Maria do Rosário (Org.). Discurso e mídia: a cultura do espetáculo. São Carlos: Claraluz, 2003. p. 111-124.

NAVARRO, Pedro Luis. Uma definição da ordem discursiva midiática. In: MILANEZ, Nilton; GASPAR. Nádea Regina (Org.). A (des)ordem do discurso. São Paulo: Contexto, 2010. p. 79-93.

PÊCHEUX, Michel. Papel da memória. In: ACHARD, Pierre et al. Papel da memória. Trad. Eni Pulcinelli Orlandi. Campina: Pontes, 1999, p. 49-57. 
EID\&A - Revista Eletrônica de Estudos Integrados em Discurso e Argumentação, Ilhéus, n. 16 esp. "Discurso e argumentação na política latino-americana, set.2018.

PIOVEZANI FILHO, Carlos Félix. Política midiatizada e mídia politizada: fronteiras mitigadas na pós-modernidade. In: GREGOLIN, Maria do Rosário. (Org.). Discurso e mídia. A cultura do espetáculo. São Carlos: Claraluz, 2003b. p. 49-64.

SÁ, Israel. A arte de dizer a política: processos de espetacularização do discurso político no Brasil. In: SARGENTINI, Vanice (Org.) Mutações do Discurso Político no Brasil: espetáculo, poder e tecnologias de comunicação. Campinas: Mercado de Letras, 2017.

ZOPPI-FONTANA, Mónica. As imagens do invisível. In: SARGENTINI, Vanice; CURCINO, Luzmara; PIOVEZANI, Carlos (Org.). Discurso, semiologia e história. São Carlos: Claraluz, 2011. p. 163-181.

Forma de citação sugerida:

SÁ, Israel de. Ditadura no Brasil e produção de memórias: o papel da grande mídia na construção de sentidos históricos. EID\&A - Revista Eletrônica de Estudos Integrados em Discurso e Argumentação, Ilhéus, n. 16 esp. "Discurso e argumentação na política latino-americana", p. 133-151, set.2018.

Recebido em: 25/07/2018

Aprovado em: 26/08/2018 